\title{
CATIONIC DYE REMOVAL BY SUGARCANE BAGASSE ACTIVATED CARBON FROM AQUEOUS SOLUTION
}

HUSSEIN M. ${ }^{2}$
HAZZAA R. ${ }^{1, *}$

Received: $12 / 09 / 2015$

Accepted: 05/11/2015

Available online: $12 / 11 / 2015$

\author{
${ }^{1}$ Petrochemical Engineering Department \\ Faculty of Engineering, Pharos University \\ Mahmoudia canal, Semouha, Alexandria, Egypt \\ ${ }^{2}$ Chemical Engineering Department, Faculty of Engineering \\ Alexandria University, Horria street, Alexandria, Egypt
}

*to whom all correspondence should be addressed: e-mail: riham17@yahoo.com; riham.hazzaa@pua.edu.eg

\begin{abstract}
Low cost agricultural waste adsorbents can be viable alternatives to activated carbon for the treatment of contaminated wastewater. Sugarcane Bagasse, an abundant agriculture waste in Egypt, was used in the present study to prepare activated carbon. Batch adsorption experiments were conducted to study its effectiveness to remove cationic dye methylene blue from aqueous solution. The effects of initial dye concentrations, agitation time, solution $\mathrm{pH}$ and temperature on methylene blue dye removal were investigated. The optimum $\mathrm{pH}$ value for the maximum percentage removal of the dye was 7. Adsorption isotherms were determined and modeled with Redlich-Peterson, Langmuir and Freundlich equations at $20^{\circ} \mathrm{C}$. The kinetic data were analyzed using Pseudo-first order, pseudo-second order. The mechanism of the adsorption process was determined from the intraparticle diffusion model. Thermodynamic parameters such as standard enthalpy $\left(\Delta H^{\circ}\right)$, standard entropy $\left(\Delta S^{\circ}\right)$ and free energy $\left(\Delta G^{\circ}\right)$ were determined. The equilibrium data were best fitted to the Redlich-Peterson isotherm model .The adsorption kinetics was found to follow the pseudo-second-order kinetic model with good correlation coefficient. The positive $\Delta \mathrm{H}^{\circ}$ value indicated that the adsorption process was endothermic in nature. The results revealed sugarcane bagasse activated carbon could be employed as a low-cost alternative adsorbent in wastewater treatment.
\end{abstract}

Keywords: Activated carbon, Methylene blue, Adsorption, Isotherm, Kinetics

\section{Introduction}

Dyes are considered to be particularly dangerous organic compounds for the environment and public health. Industries such as textile, leather, paper, plastics are sources for dye effluents. Discharging these effluents in water bodies reduces light penetration, affects photosynthesis of aqueous flora and may disturb the ecosystem (Hajati et al., 2014). Dyes can cause a severe health hazard to human beings, such as dysfunction of kidney, reproductive system, liver, brain and central nervous system, they can cause allergy, dermatitis, skin irritation (Brookstein et al., 2009) and may be mutagenic and carcinogenic to humans (De Lima et al., 2007). Methylene blue dye (MB), a cationic basic dye, is mainly used for dyeing cotton and silk (Deng et al., 2011). It can cause vomiting, nausea, hypertension and methemoglobinemia (Foo, 2012). Therefore, treatment of dyes from process effluent before discharging into receiving waters becomes environmentally important and of public health concerns. 
Various techniques have been employed for the removal of dyes from wastewaters. Adsorption was the superior to other techniques due to its flexibility, simplicity of design and ease of operation (Rafatullaha et al., 2010; Demiral et al., 2011; Vučurović et al., 2014). Adsorption by activated carbon is one of the most widely used techniques and is considered to be an effective method for the removal of dyes from wastewater. Activated carbons have high porosity and high surface area for adsorption (Spahisa et al., 2008). In addition; the chemical nature of their surfaces enhances adsorption. However, its use is limited due to its high-cost. Several studies investigated the development of activated carbon from cheap and available materials. Agricultural by-products used for the preparation of activated carbon have minimum cost moreover the benefits of the preparation of activated carbon from agricultural by-products would also include removal of polluting waste product and economic gains for products manufactured from abundant sources (Ghaedi et al., 2014). Agricultural by-products and waste materials used for the production of activated carbons include, apricot stones (Djilani et al., 2015) olive stone (Hazzaa and Hussein, 2015), pomegranate peel (Amin, 2009), bamboo (Hameed et al., 2007),coconut husk (Foo and Hameed, 2012), pistachio shell (Dolas et al. 2011), rambutan peel (Ahmad and Alrozi, 2011), walnut shells (Yang and Qiu, 2010) , and sugarcane bagasse (Silva et al., 2011)

In Egypt, sugarcane bagasse is abundantly available agricultural wastes and can be an adequate raw material to obtain good active carbon. In this study, activated carbon was prepared from sugarcane bagasse by thermal activation in absence of air. The aim of that study was to investigate the adsorptive removal of $\mathrm{MB}$ dye onto activated carbon prepared from sugarcane bagasse. Effective parameters such as $\mathrm{pH}$, initial dye concentration, agitation time, and temperature were investigated. The equilibrium and kinetic data of the adsorption were then studied. The adsorption mechanisms were investigated and thermodynamic parameters were also determined.

\section{Materials and methods}

\subsection{Adsorbate}

Cationic basic dye, methylene blue (MB) purchased from Merck was chosen as the adsorbate in this study, and was not purified prior to use. The stock solution was prepared by dissolving $1 \mathrm{~g}$ of dye in one litre double distilled water. All chemicals used, were of analytical reagent grade. The chemical formula of methylene blue dye is $\mathrm{C}_{16} \mathrm{H}_{18} \mathrm{~N}_{3} \mathrm{ClS}$ and its molecular weight is 319.85 . The $\mathrm{pH}$ of initial dye solution can be adjusted by the addition of dropwise of $0.1 \mathrm{~N} \mathrm{HCl}$ or $0.1 \mathrm{~N} \mathrm{NaOH}$ and measured using a $\mathrm{pH}$ meter. All chemicals used were of analytical reagent grade.

\subsection{Preparation of activated carbon}

Sugarcane bagasse used in the present study for production of activated carbon was collected from local markets, Egypt. It was washed thoroughly with double distilled water to remove any dust and impurities, oven dried at $105^{\circ} \mathrm{C}$ for 4 hours, crushed, and sieved to a particle size of $0.42-0.85 \mathrm{~mm}$ in diameter using standard sieves (Model \$200). Activated carbon was prepared according to our previous study (Hazzaa and Hussein 2015). Briefly the dried sugarcane bagasse was subjected to thermal activation by carbonization in a muffle furnace. The sample was placed in a 315 stainless steel covered tube in the muffle furnace, where it was physically activated and carbonized in the absence of air at different carbonization temperatures $\left(500-900^{\circ} \mathrm{C}\right.$ ) and at times (30-120 min). At the end of activation time, the carbonized samples were withdrawn from the furnace, allowed to cool and stored in tightly closed bottles. The most efficient carbonization temperature was achieved at $800^{\circ} \mathrm{C}$ and activation time $60 \mathrm{~min}$.

Scanning electron microscope (SEM) analysis was performed to study the morphology of SBAC (model SEM JEOL JSM 6360 LA Japan).

\subsection{Adsorption studies}

Batch adsorption studies were conducted in a set of $250 \mathrm{ml}$ Erlenmeyer flasks containing $1 \mathrm{~g}$ adsorbent dose of particle size $(0.42-0.85 \mathrm{~mm})$ and $100 \mathrm{ml}$ dye solutions with various initial concentrations. The 
flasks were agitated in an isothermal water-bath shaker at $150 \mathrm{rpm}$ and $20 \pm 1{ }^{\circ} \mathrm{C}$. The samples were taken at different time intervals until the equilibrium was reached. The experimental data were analysed for equilibrium and kinetic studies. The effects of initial concentration of $M B\left(10,30,50,70\right.$ and $\left.100 \mathrm{mg} \mathrm{l}^{-1}\right)$, agitation time (5-120 $\mathrm{min}), \mathrm{pH}$ of the solution (2-9) and the temperature $\left(20,30,40\right.$ and $\left.50{ }^{\circ} \mathrm{C}\right)$ on the adsorptive removal of $\mathrm{MB}$ were investigated. The samples withdrawn were centrifuged for $10 \mathrm{~min}$ and $1000 \mathrm{rpm}$. The dye concentration before and after adsorption were determined using UV-vis spectrophotometer (Shimadzu UV-1601, Japan) at wavelength $660 \mathrm{~nm}$. All experiments were performed in duplicates. $M B$ uptake at time $t, q_{t}\left(\mathrm{mgg}^{-1}\right)$, and at equilibrium, $\mathrm{q}_{\mathrm{e}}\left(\mathrm{mgg}^{-1}\right)$, was calculated by the following equation:

$$
\begin{aligned}
& q_{t}=\frac{\left(C_{i}-C_{t}\right)}{W} \times V \\
& q_{e}=\frac{\left(C_{i}-C_{e}\right)}{W} \times V
\end{aligned}
$$

where $C_{i}, C_{e}$ and $C_{t}\left(\mathrm{mg} \mathrm{l}^{-1}\right)$ are the initial , equilibrium concentrations, and concentration at time $t$ of dye, respectively, $\mathrm{V}(\mathrm{I})$ is the volume of the solution, and $\mathrm{W}(\mathrm{g})$ is the mass of adsorbent used

The percentage removal of MB was calculated as follows:

$$
\mathrm{R} \%=\frac{\left(\mathrm{C}_{\mathrm{i}}-\mathrm{C}_{\mathrm{e}}\right)}{\mathrm{C}_{\mathrm{i}}} \times 100
$$

\section{Results and discussion}

\subsection{Scanning electron microscopy}

Figure 1 shows SEM micrograph of the SBAC with different magnification power. The carbonization of sugarcane created pores and holes. The produced activated carbon presented a uniform porous structure. The surfaces of the thermally carbonized carbons are full of cavities indicating the possibility for the dye to be adsorbed.

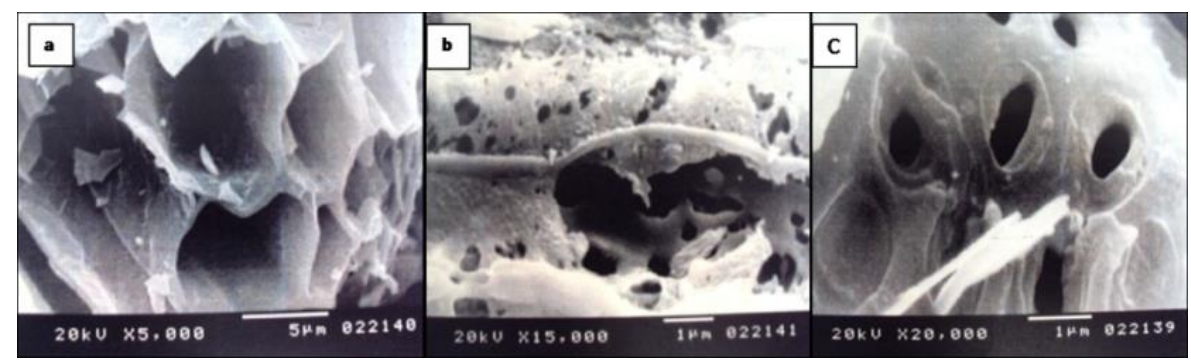

Figure 1. Scanning electron micrographs (SEM) of SBAC (a) magnification 5000, (b) magnification 15000, (c) magnification 20000

\subsection{Batch adsorption experiments}

\subsubsection{Effect of initial concentration of dye and agitation time on adsorption}

The effect of agitation time and initial concentration of MB in the solution on adsorption onto the SBAC was studied and shown in Figure 2. The experiments were carried out at adsorbent dose $1 \mathrm{~g} / 100 \mathrm{ml}$, temperature $20^{\circ} \mathrm{C}, \mathrm{pH} 7$ and at different initial concentrations of $\mathrm{MB}\left(10,30,50,70\right.$ and $\left.100 \mathrm{mg} \mathrm{l}^{-1}\right)$ for different time intervals. The results showed that the $M B$ removal was fast at the initial stages of the contact time, and slowed down near equilibrium. Fig. 2 showed rapid removals of dye in the first 20 min which indicates a high degree of affinity of the interacting groups on the surface of the activated carbon. 
The contact time needed for $\mathrm{MB}$ solutions with initial concentrations of $10 \mathrm{mg}^{\mathrm{I}^{-1}}$ to reach equilibrium was less than $60 \mathrm{~min}$. However, for MB solutions with initial concentrations $100 \mathrm{mg}^{-1}$ longer equilibrium times were reached at $120 \mathrm{~min}$. The results revealed that the percentage removal of dye decreased with an increase in initial dye concentration, which may be due to the saturation of adsorption sites on the adsorbent surface (Salleh et al., 2011). The percentage removal of MB adsorbed decreased from $88 \%$ to $55 \%$ as the initial concentration increased from 10 to $100 \mathrm{mg} \mathrm{l}^{-1}$. A large number of vacant surface sites were available for adsorption during the initial stage, and after a period of time, the remaining vacant surface sites were occupied. At low concentrations there will be unoccupied active sites on the adsorbent surface, and when the initial dye concentration increases, the active sites required for adsorption of the dye molecules will not be available. Similar results were reported in previous studies (Hameed et al., 2007; El Nemr et al., 2009).

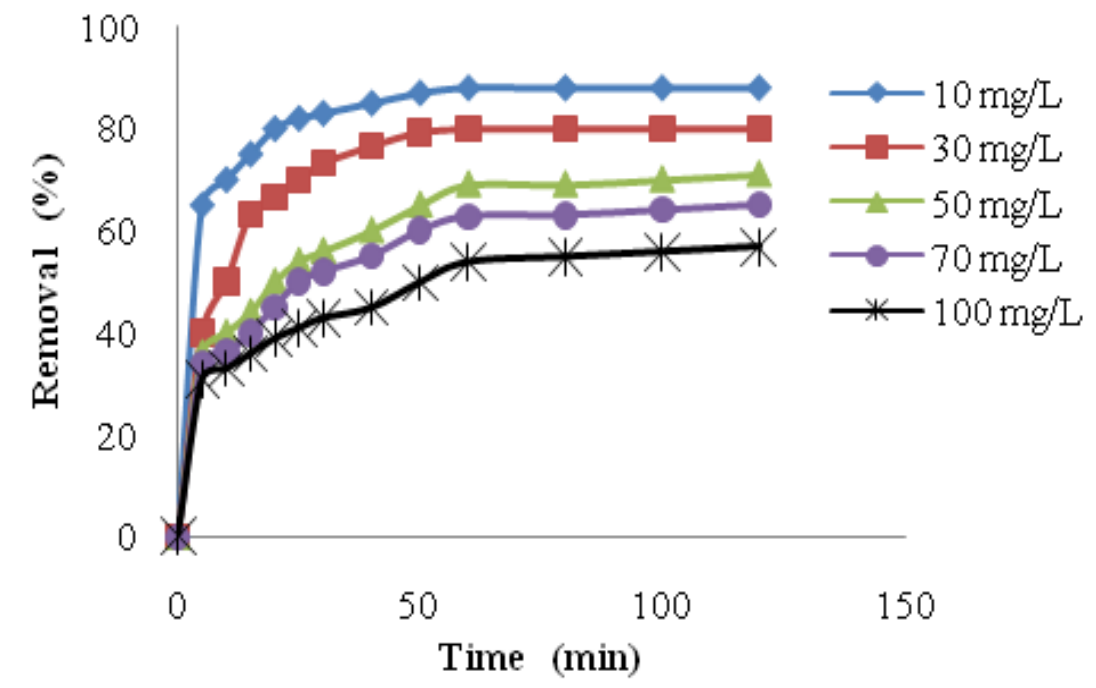

Figure 2. Effect of agitation time on adsorption of $M B$ at various initial concentrations ( Temperature $=20^{\circ} \mathrm{C}, \mathrm{pH}=7, \mathrm{SBAC}$ dose $=10 \mathrm{gL}^{-1}$, agitation speed $=150 \mathrm{rpm}$ ).

\subsubsection{Effect of solution $\mathrm{pH}$ on adsorption}

The $\mathrm{pH}$ factor is an important factor in the adsorption process can significantly influence adsorption of dyes. The effect of solution $\mathrm{pH}$ on MB removal by SBAC in $\mathrm{pH}$ range of 2-9 with initial MB concentration of $100 \mathrm{mg} \mathrm{l}^{-1}$, SBAC dosage of $1 \mathrm{~g} / 100 \mathrm{ml}$ and adsorption temperature of $20^{\circ} \mathrm{C}$ was shown in Figure 3 .

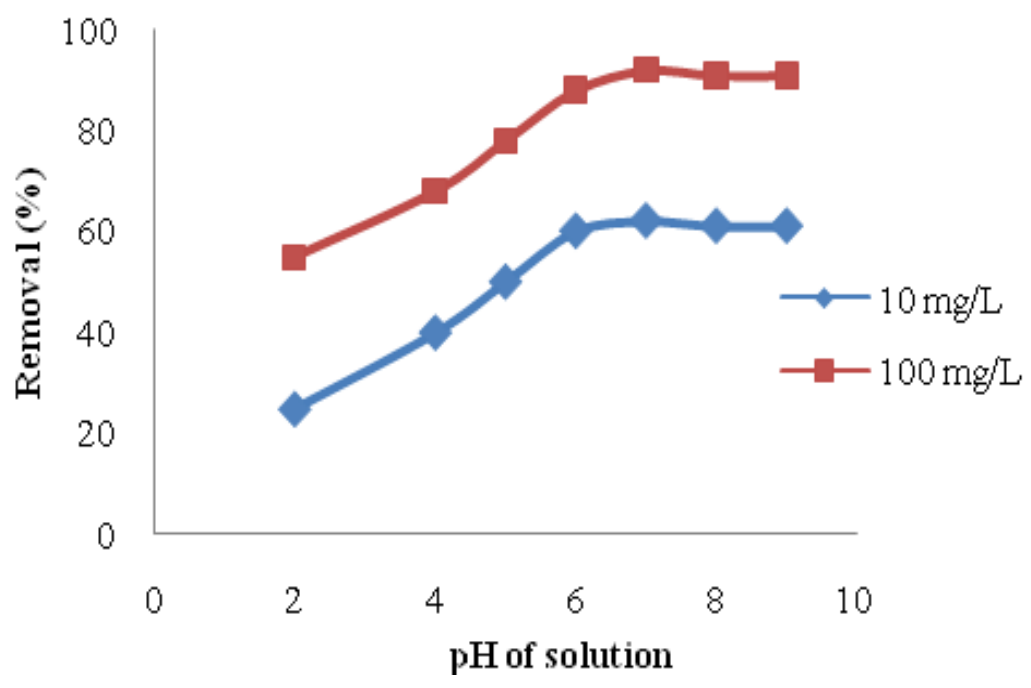

Figure 3. Effect of solution $\mathrm{pH}$ on $\mathrm{MB}$ adsorbed by SBAC 
It can be seen that the dye removal efficiencies by SBAC increase with increasing $\mathrm{pH}$. At $\mathrm{pH} 2$ the percentage removal of dye was $25 \%$ and $55 \%$ for initial concentration $10 \mathrm{mg} \mathrm{l}^{-1}$ and $100 \mathrm{mg} \mathrm{l}^{-1}$ respectively, while, at $\mathrm{pH} 7$ the percentage removal of dye was $62 \%$ and $90 \%$ for initial concentration $100 \mathrm{mg} \mathrm{l}^{-1}$ and $10 \mathrm{mgL}^{-1}$ respectively. Similar observations were previously reported (El-Sayed, 2011). The percentage removal MB dye on the SBAC was minimum at lower $\mathrm{pH}$ may be due to the competing proton ions with the cationic MB dye for the adsorption on the SBAC. However, at higher solution $\mathrm{pH}$, the number of negatively charged surface sites on the adsorbent increased which may increase the electrostatic attractions between the positively charged dye cations and negatively charged adsorption sites, thus increased the removal of dye (Al-Degs, 2008).

\subsubsection{Effect of temperature on adsorption}

The effect of solution temperature on the adsorption process was studied by varying the adsorption temperature at $20,30,40$ and $50^{\circ} \mathrm{C}$, adsorbent dose $1 \mathrm{gm}$ and initial dye concentration of MB $10 \mathrm{mg} \mathrm{l}^{-1}$ and $100 \mathrm{mg} \mathrm{l}^{-1}$ of MB. Figure 4 shows that increasing the temperature from $20-50{ }^{\circ} \mathrm{C}$; increase the percentage removal from $60 \%$ to $85 \%$ respectively for initial concentration of MB $100 \mathrm{mg} \mathrm{l}^{-1}$. However for initial concentration of $\mathrm{MB} 10 \mathrm{mg} \mathrm{l}^{-1}$ the percentage removal increased from $92 \%$ to $99 \%$ for the increase of temperature from $20-50{ }^{\circ} \mathrm{C}$ respectively. Increasing temperature may decrease the viscosity of the solution and increase the rate of diffusion of the dye to the external boundary layer and the internal pores of the activated carbon. Similar results were also reported. (Gürses et al., 2014 ).

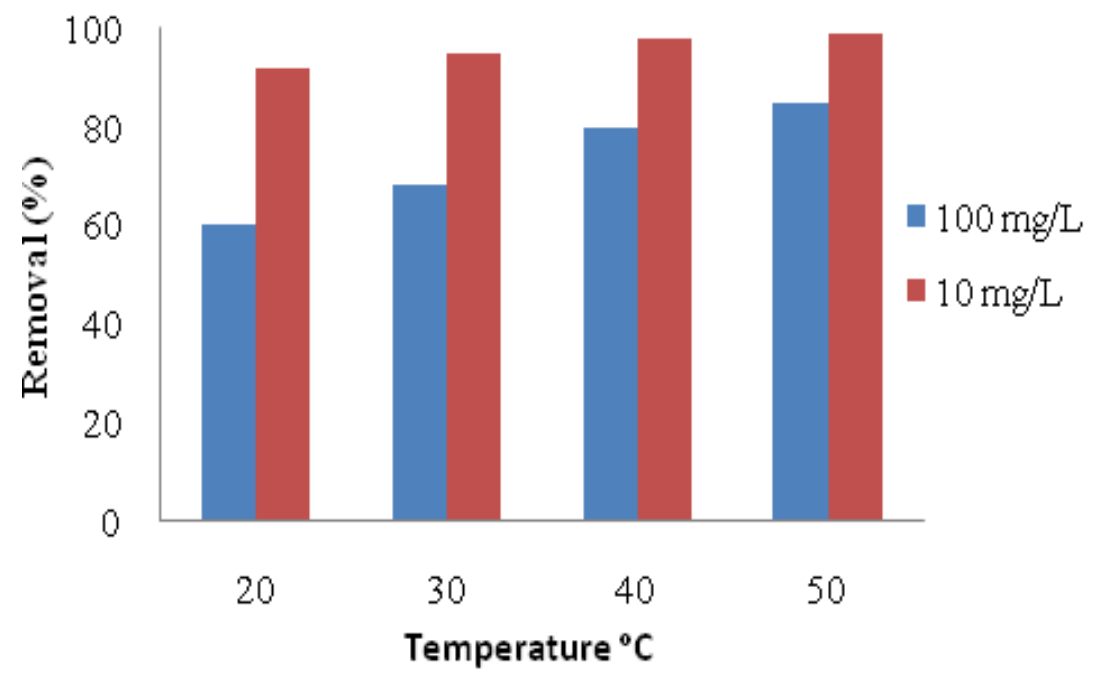

Figure 4. Effect of temperature on MB adsorption

\subsection{Adsorption Isotherms}

The adsorption equilibrium data for $\mathrm{MB}$ onto SBAC were analysed by using a non-linear regression by MATLAB 2014@ to fit the two parameter and three parameter isotherm models. In this work, the Langmuir, the Freundlich and the Redlich-Peterson isotherm models were tested. The correlation coefficient $\left(R^{2}\right)$ and the adjusted correlation coefficient $\left(R^{2}\right.$ adj $)$ give the quality of fitting. The statistical indices; the sum squares errors (SSE) and root mean square errors (RMSE) were calculated to evaluate the goodness obtained fits according to the following equations:

$$
\begin{aligned}
& \text { SSE }=\left(q e_{\text {cal }}-q_{\text {exp }}\right)^{2} \\
& \text { RMSE }=\sqrt{\frac{\sum\left(q_{e_{\text {cal }}}-q_{e_{\text {exp }}}\right)^{2}}{N}}
\end{aligned}
$$


where qe $e_{\text {exp }}$ is experimental value of qe, $\mathrm{qe}_{\text {cal }}$ is the predicted value of qe by models, $\mathrm{N}$ indicates the number of data points in the experimental run.

The Langmuir isotherm assumes (Langmuir, 1918) that uptake occurs on homogeneous surface by monolayer sorption monolayer adsorption. Langmuir isotherm equation is given as:

$$
q_{e}=\frac{Q_{m} K_{L} C_{e}}{1+K_{L} C_{e}}
$$

where $\mathrm{q}_{\mathrm{e}}$ is the amount of solute adsorbed per unit weight of adsorbent at equilibrium $\left(\mathrm{mgg}^{-1}\right), \mathrm{C}_{\mathrm{e}}$ the equilibrium concentration of the solute in the bulk solution $\left(\mathrm{mg} \mathrm{l}^{-1}\right), \mathrm{q}_{\mathrm{m}}$ the maximum adsorption capacity $\left(\mathrm{mgg}^{-1}\right)$, and $\mathrm{K}_{\mathrm{L}}$ is Langmuir isotherm constant $\left(\mathrm{mg}^{-1}\right)$.

The essential characteristics of the Langmuir isotherm can be expressed in terms of dimensionless constant separation factor, $R_{L}$, is calculated by the following equation

$$
R_{L}=\frac{1}{1+K_{L} C_{O}}
$$

Separation factor indicates the nature of adsorption as $0<R_{L}<1$ (favourable). The isotherm parameters, the coefficient of correlation values and the statistical indices were shown in Table 1 . The value of $R_{\mathrm{L}}$ was the 0.55 and 0.11 at initial dye concentration $10 \mathrm{mg} \mathrm{l}^{-1}$ and $100 \mathrm{mg} \mathrm{l}^{-1}$, respectively, showing that the adsorption of $\mathrm{MB}$ on $\mathrm{SBAC}$ is favourable. The $\mathrm{R}_{\mathrm{L}}$ values decreased with increase in initial dye concentration. This shows that the adsorption process is favourable at higher dye concentration (Mi-Hwa et al., 2010).

The Freundlich equilibrium isotherm equation is an empirical equation used for the description of multilayer adsorption with interaction between adsorbed molecules:

$$
\mathrm{q}_{\mathrm{e}}=\mathrm{K}_{\mathrm{F}} \mathrm{C}_{\mathrm{e}}^{\frac{1}{n}}
$$

where $\mathrm{K}_{\mathrm{F}}$ is the Freundlich isotherm constant (Freundlich,1906) and $\mathrm{n}$ represents the adsorption intensity, $\mathrm{C}_{\mathrm{e}}$ indicates the equilibrium concentration of adsorbate $\left(\mathrm{mgL}^{-1}\right), \mathrm{q}_{\mathrm{e}}$ is the amount of adsorbate adsorbed per gram of the adsorbent at equilibrium $\left(\mathrm{mgg}^{-1}\right)$. The model is applicable to the adsorption on heterogeneous surfaces by a uniform energy distribution and reversible adsorption. The magnitude of the exponent $n$ gives an indication on the favorability of adsorption. It is generally stated that values of $n$ in the range $1<n<10$ represent good adsorption. The Freundlich isotherm parameters, the correlation coefficient values, SSE and RMSE values were listed in Table 1. The results revealed that there is a good agreement between the experimental and predicted values, suggesting that the Freundlich model is valid for the experimental equilibrium data. Freundlich isotherm is more suitable for the experimental results than is the Langmuir expression because of the lower SSE and RMSE values.

The Redlich-Peterson isotherm (Redlich and Peterson, 1959) is an empirical isotherm incorporating three parameters. It combines elements from both the Langmuir and Freundlich equations, and the mechanism of adsorption is a hybrid and does not follow ideal monolayer adsorption:

$$
\mathrm{q}_{\mathrm{e}}=\frac{\mathrm{k}_{\mathrm{RP}} \mathrm{C}_{\mathrm{e}}}{1+\mathrm{a}_{\mathrm{RP}}{ }^{*} \mathrm{C}_{\mathrm{e}}^{\beta}}
$$

Where; $K_{R P}$ is the Redlich-Peterson isotherm constant $\left(\mathrm{g} \mathrm{g}^{-1}\right)$, $\mathrm{a}_{\mathrm{RP}}$ is also a constant having unit of $\left(\mathrm{Img}^{-1}\right)^{\beta}$, and $\beta$ is an exponent that lies between 0 and $1 . C_{e}$ is the equilibrium liquid-phase concentration of the adsorbate $\left(\mathrm{mg} \mathrm{l}^{-1}\right)$ and $\mathrm{q}_{\mathrm{e}}$ is the equilibrium adsorbate loading onto the adsorbent $\left(\mathrm{mgg}^{-1}\right)$.

The results present that the SSE and RMSE error values are least while $R^{2}$ adj and $R^{2}$ values approach to one for the Redlich-Peterson model followed by Freundlich and Langmuir models. All the evaluated equilibrium models gave good fit to the experimental data. 
Table 1. Parameters of the Redlich- Peterson, Freundlich and Langmuir isotherms for the adsorption of $\mathrm{MB}$ dye onto SBAC

\begin{tabular}{|c|c|c|c|c|c|c|}
\hline Isotherms models & \multicolumn{2}{|c|}{ Isotherms parameter } & SSE & RMSE & $\mathbf{R}_{\text {adj }}^{2}$ & $\mathbf{R}^{2}$ \\
\hline \multirow{3}{*}{ Langmuir } & $\mathrm{Q}_{\mathrm{m}}\left(\mathrm{mgg}^{-1}\right)$ & 6.739 & \multirow{3}{*}{0.2775} & \multirow{3}{*}{0.3041} & \multirow{3}{*}{0.971} & \multirow{3}{*}{0.9782} \\
\hline & $\mathrm{R}_{\mathrm{L}}$ & $0.55-0.11$ & & & & \\
\hline & $\mathrm{K}_{\mathrm{L}}\left(\mathrm{Lmg}^{-1}\right)$ & 0.08061 & & & & \\
\hline \multirow{2}{*}{ Freundlich } & $K_{F}\left(m g^{1-(1 / n)} L^{1 / n} g^{-1}\right.$ & 1.005 & \multirow{2}{*}{0.07613} & \multirow{2}{*}{0.1593} & \multirow{2}{*}{0.992} & \multirow{2}{*}{0.994} \\
\hline & $\mathrm{n}$ & 2.224 & & & & \\
\hline \multirow{3}{*}{ Redlich- Peterson } & $\mathrm{K}_{\mathrm{RP}}\left(\mathrm{L} \mathrm{g}^{-1}\right)$ & 1.695 & \multirow{3}{*}{0.02333} & \multirow{3}{*}{0.108} & \multirow{3}{*}{0.9963} & \multirow{3}{*}{0.9982} \\
\hline & $a_{R P}\left(m g L^{-1}\right)^{-\beta}$ & 1.057 & & & & \\
\hline & $\beta$ & 0.6574 & & & & \\
\hline
\end{tabular}

However the Redlich-Peterson is the best model describing adsorption of MB on the SBAC. The results of this study revealed that best isotherm models fitted for $M B$ adsorption were determined in the order: Redlich-Peterson > Freundlich > Langmiur. Equilibrium isotherms of methylene blue adsorption were previously investigated by other researchers (Hameed and El-Khaiary, 2008; Yener et al., 2008; Tan et al., 2007; Hameed et al., 2007; Tan et al., 2008). The monolayer adsorption capacities of MB on SBAC $6.73 \mathrm{mg} \mathrm{g}^{-1}$. Table 2 lists a comparison of adsorption capacities of methylene blue dye onto different adsorbents.

Table 2 .The adsorption capacity for methylene blue by various adsorbents

\begin{tabular}{ccc}
\hline Adsorbent & Maximum monolayer & \multicolumn{2}{l}{ References } \\
\hline Qm & 28.5 & Reddy et al. 2015 \\
\hline Rice husk activated carbon & 16.12 & Hazzaa and Hussein 2015 \\
\hline Olive stone activated carbon & 25.51 & Dutta et al. 2011 \\
\hline Citrus fruit peel carbon & 5.87 & Kavitha and Namasivayam 2007 \\
\hline Coir pith carbon & 8.82 & Aygun 2003 \\
\hline Hazelnut shell-activated carbon & 6.73 & Present study \\
\hline Sugarcane bagasse activated carbon & &
\end{tabular}

\subsection{Adsorption kinetics}

The pseudo-first-order (PFO) kinetic model( Langergren and Svenska 1898) is given by

$$
\ln \left(q_{e}-q_{t}\right)=\ln q_{e}-k_{1} t
$$

where $\mathrm{q}_{\mathrm{e}}$ and $\mathrm{q}_{\mathrm{t}}\left(\mathrm{mg} \mathrm{g}^{-1}\right)$ are the amounts of adsorbate adsorbed at equilibrium and at any time respectively and $k_{1}\left(\mathrm{~min}^{-1}\right)$ is the rate constant. The plot of $\ln \left(\mathrm{q}_{\mathrm{e}}-\mathrm{q}_{\mathrm{t}}\right)$ versus $t$ is not shown. The values of $k_{1}$ and correlation coefficient, $R^{2}$ were listed in Table 2. Although the $R^{2}$ values were relatively high $\left(R^{2}>\right.$ 0.95) for initial concentration of $10-100 \mathrm{mg}^{-L^{-1}}$, the experimental $q_{\mathrm{e}, \mathrm{exp}}$ values did not agree with the calculated $q_{\mathrm{e}, \text { cal }}$ values obtained from the linear plots. This reveals that the adsorption of MB onto the SBAC does not follow PFO kinetic model.

The pseudo-second-order (PSO) model (McKay and Ho 1999) is given as follows:

$$
\frac{t}{q}=\frac{1}{k_{2} q_{e}^{2}}+\frac{1}{q_{e}} t
$$

where $k_{2}$ is the rate constant of adsorption $\left(\mathrm{g} \mathrm{mg}^{-1} \mathrm{~min}^{-1}\right)$. The values of $\mathrm{q}_{\mathrm{e}}$ and $\mathrm{k}_{2}$ are determined from the slope and intercept of the plot of $t / q_{t}$ against $t$ as shown in Figure 5 and listed in table 2 . The correlation coefficient values, $\mathrm{R}^{2}$ for the second-order kinetic model were almost equal to unity for $10 \mathrm{mg} \mathrm{l}^{-1}$ and $30 \mathrm{mg} \mathrm{l}^{-1}$ concentrations of MB and larger than 0.987 for $50 \mathrm{mg} \mathrm{l}^{-1}, 70 \mathrm{mg} \mathrm{l}^{-1}$ and $100 \mathrm{mg} \mathrm{l}^{-1}$ concentration of $\mathrm{MB}$. 


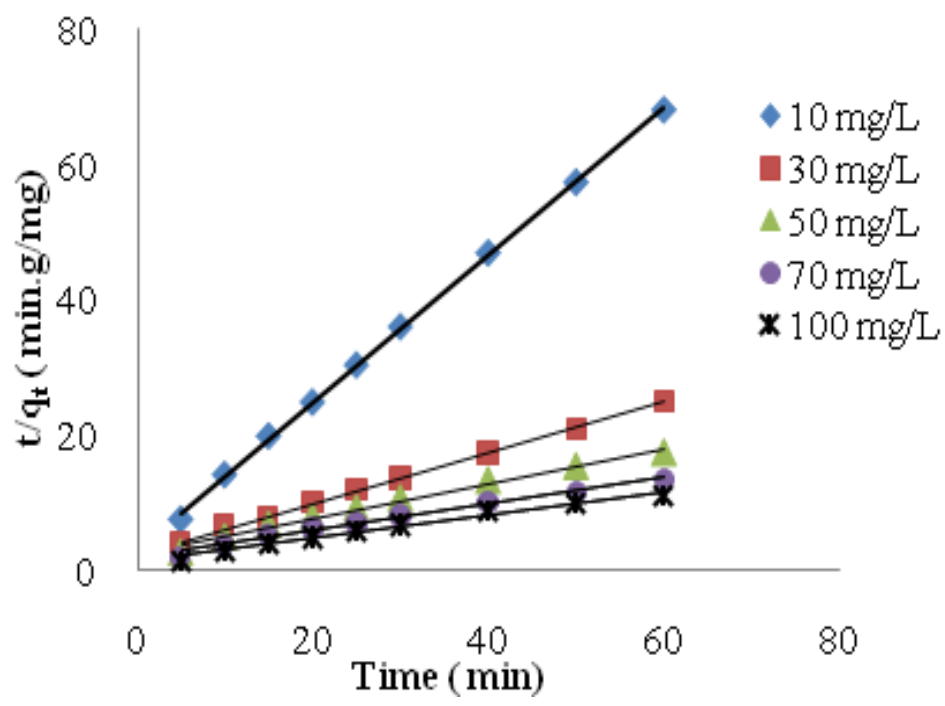

Figure 5: Pseudo-second-order kinetics for adsorption of MB on SBAC

Moreover the calculated $q_{\mathrm{e}, \text { cal }}$ values agree with the experimental data. This reveals that the adsorption of MB on SBAC follows to the pseudo-second-order kinetic model. These results come in agreement with previous studies (Li, 2013). Table 3 also shows that $\mathrm{K}_{2}$ decreased with increasing initial concentration of MB. These results agreed with previous studies (Hameed and El-Khaiary, 2008 and Chen et al., 2010). Also the results show that increasing the initial concentration of $M B$ increases the initial adsorption rate $\left(h=k_{2} q_{e}^{2}\right)$. Similar results have been previously reported (Belaid et al., 2013). It was stated that the quantity of the rate of adsorption $\mathrm{k}_{2} \mathrm{q}_{\mathrm{e}}$ was exactly the inverse of the half-life of adsorption process $\left(\mathrm{t}_{1 / 2}\right)$.

Table 3. Kinetics parameters of MB adsorption onto SBAC

\begin{tabular}{cccccccccr}
\hline $\mathrm{C}_{0}\left(\mathrm{mg} \mathrm{l}^{-1}\right)$ & $\begin{array}{c}\mathrm{q}_{\text {exp }} \\
\left(\mathrm{mg} \mathrm{g}^{-1}\right)\end{array}$ & $\begin{array}{c}\mathrm{q}_{\mathrm{e}, \text { cal }} \\
\left(\mathrm{mg} \mathrm{g}^{-1}\right)\end{array}$ & $\begin{array}{c}\mathrm{K}_{1} \\
\left(\mathrm{~min}^{-1}\right)\end{array}$ & $\mathrm{R}^{2}$ & $\begin{array}{c}\mathrm{q}_{\mathrm{e}, \text { cal }} \\
\mathrm{mg} \mathrm{g}^{-1}\end{array}$ & $\begin{array}{c}\mathrm{K}_{2} \mathrm{~g} \\
(\mathrm{mg} \mathrm{min})^{-1}\end{array}$ & $\begin{array}{c}\mathrm{K}_{2} \mathrm{q}_{\mathrm{e}} \\
\mathrm{min}^{-1}\end{array}$ & $\begin{array}{c}\mathrm{h}=\mathrm{k}_{2} \mathrm{q}_{\mathrm{e}}^{2} \\
\mathrm{mg}\left(\mathrm{g} \cdot \mathrm{min}^{-1}\right.\end{array}$ & $\mathrm{R}^{2}$ \\
\hline 10 & 0.88 & 0.338 & 0.066 & 0.983 & 0.918 & 0.373 & 0.343 & 0.315 & 0.999 \\
\hline 30 & 2.4 & 2.110 & 0.084 & 0.966 & 2.68 & 0.055 & 0.147 & 0.397 & 0.999 \\
\hline 50 & 3.45 & 2.316 & 0.045 & 0.973 & 3.861 & 0.026 & 0.103 & 0.398 & 0.987 \\
\hline 70 & 4.41 & 2.712 & 0.041 & 0.989 & 4.975 & 0.020 & 0.101 & 0.503 & 0.987 \\
\hline 100 & 5.5 & 3.095 & 0.029 & 0.964 & 5.847 & 0.019 & 0.116 & 0.679 & 0.980 \\
\hline
\end{tabular}

\subsection{Adsorption mechanism}

Intraparticle diffusion model (Weber and Morris, 1963) was used to describe adsorption mechanism. The intraparticle diffusion model is given as follows

$$
q_{t}=k_{\text {diff }} t^{1 / 2}+C
$$

where $K_{\text {diff }}$ is the intra-particle diffusion rate constant $\left(\operatorname{mg}(\operatorname{gmin})^{-1}\right)$, and $C_{i}$ is a constant indicates the thickness of the boundary layer $\left(\mathrm{mgg}^{-1}\right)$. The intraparticle diffusion plots of the experimental results, $\mathrm{q}_{\mathrm{t}}$ versus $t^{1 / 2}$ for different adsorbent are shown in Figure 6 . The values of $K_{\text {diff, }} C_{i}$ and correlation coefficient $\mathrm{R}^{2}$ are listed in Table4. The values of $\mathrm{C}_{\mathrm{i}}$ obtained from intraparticle diffusion model indicate that thickness of the boundary layer increased by increasing the initial MB concentration and that intraparticle diffusion may not be the controlling factor in the adsorption process. The results revealed that more than one process affected the adsorption and the adsorption process contains both the surface adsorption and intraparticle diffusion. These observations have been reported by others (Yu and Luo, 2014). 


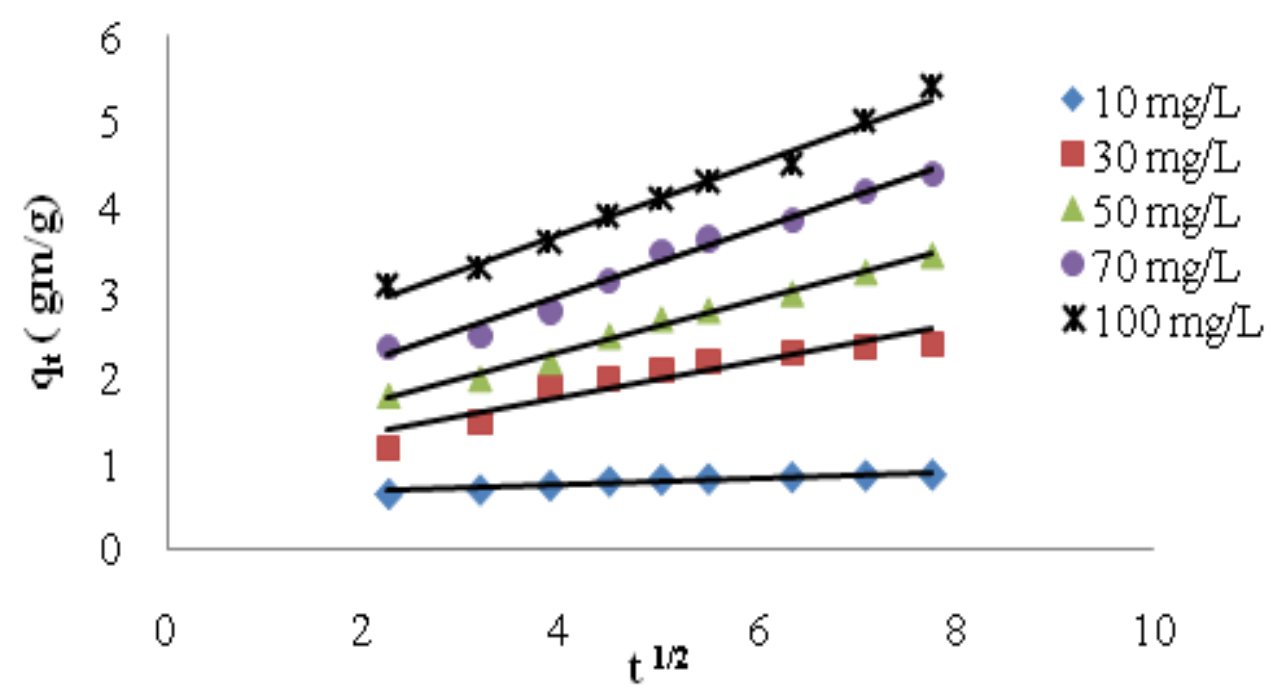

Figure 6. Intraparticle diffusion plot for methylene blue onto SBAC

The film diffusion coefficient $\left(D_{F}\right)$ and pore diffusion coefficient $\left(D_{P}\right)$ are parameters of the kinetic study of the adsorption process. The diffusion coefficients were calculated by method based on adsorption rate proposed .Assuming that the sorbent particles are spherical, half time equations of film and pore diffusions can be calculated from the equations (Anirudhan and Ramachandran, 2014):

$$
\begin{aligned}
& t_{1 / 2}=\frac{0.03 r^{2}}{D_{P}} \\
& t_{1 / 2}=0.23 r * \frac{\delta}{D_{F}} * \frac{C}{C_{e}}
\end{aligned}
$$

where $r$ is the radius of the adsorbent $\delta$ is the film thickness, $C$ and $C_{e}$ are the concentrations of adsorbate on the adsorbent and in solution at equilibrium state, respectively. The adsorbent was assumed to be in spherical form, and the film thickness is taken as $10^{-3} \mathrm{~cm}$. The film diffusion is the rate limiting step if the values of film diffusion coefficients are in the range of $10^{-6}-10^{-8} \mathrm{~cm}^{2} . \mathrm{s}^{-1}$ but if pore diffusion coefficient is in the range of $10^{-11}-10^{-13} \mathrm{~cm}^{2} \cdot \mathrm{s}^{-1}$, the pore diffusion coefficients will be rate limiting. The results reveal that the magnitude of the coefficient $D_{f}$ is on the order of $10^{-7}$ and $10^{-6} \mathrm{~cm}^{2} \cdot \mathrm{s}^{-1}$, indicating that film diffusion is the rate limiting step (Anirudhan and Ramachandran, 2014).

Table4. Intraparticle diffusion parameter and diffusion coefficients values

\begin{tabular}{cccccc}
\hline $\begin{array}{c}\text { Concentration } \\
\mathrm{mg} \mathrm{l}^{-1}\end{array}$ & $\begin{array}{c}\mathrm{K}_{\text {diff }} \\
\mathrm{mgg}^{-1} \mathrm{~min}^{-1 / 2}\end{array}$ & $\mathrm{C}_{\mathrm{i}}\left(\mathrm{mgg}^{-1}\right)$ & $\mathrm{R}^{2}$ & $\begin{array}{c}\text { Film diffusion } \\
\mathrm{D}_{\mathrm{F}} \mathrm{Cm}^{2} \mathrm{~min}^{-1}\end{array}$ & $\begin{array}{c}\text { Pore diffusion } \\
\mathrm{D} \mathrm{cm}^{2} \mathrm{~min}^{-1}\end{array}$ \\
\hline 10 & 0.041 & 0.583 & 0.924 & $11.5 \times 10^{-6}$ & $4.10 \times 10^{-6}$ \\
\hline 30 & 0.213 & 0.923 & 0.891 & $2.71 \times 10^{-6}$ & $1.76 \times 10^{-6}$ \\
\hline 50 & 0.307 & 1.082 & 0.992 & $1.02 \times 10^{-6}$ & $1.20 \times 10^{-6}$ \\
\hline 70 & 0.392 & 1.402 & 0.983 & $7.73 \times 10^{-7}$ & $1.19 \times 10^{-6}$ \\
\hline 100 & 0.415 & 2.039 & 0.984 & $5.99 \times 10^{-7}$ & $1.33 \times 10^{-6}$ \\
\hline
\end{tabular}

\subsection{Adsorption thermodynamics}

Thermodynamic considerations of an adsorption process are necessary to conclude whether the process is spontaneous or not. Thermodynamic parameters such as Gibbs free energy change $\left(\Delta G^{\circ}\right)$, enthalpy change $\left(\Delta \mathrm{H}^{\circ}\right)$ and the entropy change $\left(\Delta \mathrm{S}^{\circ}\right)$ can be estimated using equilibrium constants changing with 
temperature. The Gibbs free energy change of the adsorption reaction can be determined from the following equation:

$$
\Delta G^{\circ}=-R T \ln K D
$$

The KD value was calculated using the following equation:

$$
K D=\frac{q_{e}}{C_{e}}
$$

Relation between $\Delta \mathrm{G}^{\circ},\left(\Delta \mathrm{H}^{\circ}\right)$ and $\left(\Delta \mathrm{S}^{\circ}\right)$ can be expressed by the following equations:

$$
\Delta G^{\circ}=\Delta H^{\circ}-T \Delta S^{\circ}
$$

$$
\ln K D=-\frac{\Delta G^{\circ}}{R T}=-\frac{\Delta H^{\circ}}{R T}+\frac{\Delta S^{\circ}}{R}
$$

where $\mathrm{R}\left(8.314 \mathrm{~J} \mathrm{~mol}^{-1} \mathrm{~K}^{-1}\right)$ is the universal gas constant, $T(\mathrm{~K})$ is the absolute solution temperature. According to equation (18), $\Delta \mathrm{H}^{\circ}$ and $\Delta \mathrm{S}^{\circ}$ parameters are calculated from the slope and intercept of the van't Hoff plot of In KD versus $1 / T$, respectively, listed in Table 5. The positive $\Delta H^{\circ}$ value obtained indicated that the adsorption process was endothermic in nature, which is in agreement with the experimental observations.

Table5. Thermodynamic parameters for adsorption of MB onto SBAC

\begin{tabular}{ccccc}
\hline \multirow{2}{*}{ Parameters } & \multicolumn{3}{c}{ Temperature K } \\
\cline { 2 - 5 } & \multicolumn{1}{c}{293} & 303 & 313 & 323 \\
\hline$\Delta \mathrm{G}^{\circ} \mathrm{kJ} \mathrm{mol}^{-1}$ & 4.621388 & 3.901681 & 2.384447 & 1.525277 \\
$\Delta \mathrm{H}^{\circ} \mathrm{kJ} \mathrm{mol}^{-1}$ & 36.32387 & & & \\
$\Delta \mathrm{S}^{\circ} \mathrm{J} \mathrm{mol}^{-1} \mathrm{~K}^{-1}$ & 107.8326 & & & \\
$\mathrm{R}^{2}$ & 0.984 & & & \\
\hline
\end{tabular}

Similar phenomena had been previously reported by other authors (Wang and Zhu, 2007). The positive values of $\Delta S^{\circ}$ obtained showed the affinity of the SBAC for MB and the increasing randomness at the solidsolution interface and the positive values of $\Delta \mathrm{G}^{\circ}$ obtained indicated the non-spontaneous nature of the adsorption process at the range of temperatures being studied.

\section{Conclusions}

Activated carbon has been prepared from sugarcane bagasse for removal of methylene blue dye from aqueous solutions. The maximum removal of methylene blue was attained at $\mathrm{pH}$. The adsorption equilibrium was reached within 60 and 120 min for initial dye concentration $10 \mathrm{mg} \mathrm{l}^{-1}$ and $100 \mathrm{mg} \mathrm{l}^{-1}$ respectively. The three-parameter isotherm models as well as two-parameter models were found to be applicable for the adsorption equilibrium data by non-linear regression. The Redlich-Peterson is the best model describing adsorption of MB on the SBAC. The SSE and RMSE error values are least and $\mathrm{R}^{2}$ values approach to one. The adsorption process is governed by the pseudo-second order reaction, at various initial dye concentrations. Thermodynamic studies indicated that the adsorption process is endothermic. The results indicated that sugarcane bagasse activated carbon could be used as a low-cost adsorbent for the removal of methylene blue from wastewater.

\section{References}

Ahmad M.A. and Alrozi R. (2011), Optimization of rambutan peel based activated carbon preparation conditions for Remazol Brilliant Blue R removal, Chemical Engineering Journal, 166, 280-285.

Al-Degs Y.S., El-Barghouthi M.I., El-Sheikh A.H. and Walker G.A. (2008), Effect of solution pH, ionic strength, and temperature on adsorption behavior of reactive dyes on activated carbon, Dyes and Pigments, 77, 16-23. 
Amin N.K. (2009), Removal of direct blue-106 dye from aqueous solution using new activated carbons developed from pomegranate peel: Adsorption equilibrium and kinetics, Journal of Hazardous Materials, 165, 52-62.

Anirudhan T.S. and Ramachandran M. (2014), Removal of 2,4,6-trichlorophenol from water and petroleum refinery industry effluents by surfactant-modified bentonite, Journal Water Process Engineering, 1, 46-53.

Aygun A., Yenisoy-Karakas S. and Duman I. (2003), Production of granular activated carbon from fruit stones and nutshells and evaluation of their physical, chemical and adsorption properties, Microporous Mesoporous Material, 66,189- 95.

Belaid K.D., Kacha S., Kameche M. and Derriche Z. (2013), Adsorption kinetics of some textile dyes onto granular activated carbon, Journal of Environmental Chemical Engineering, 1, 496-503.

Brookstein D.S. (2009), Factors associated with textile pattern dermatitis caused by contact allergy to dyes, finishes, foams, and preservatives, Dermatol. Clin, 27, 309-322.

Chen S., Zhang J., Zhang C., Yue Q., Li Y. and Li C. (2010), Equilibrium and kinetic studies of methyl orange and methyl violet adsorption on activated carbon derived from Phragmites australis, Desalination, 252, 149-156.

De Lima R.O.A., Bazo A.P., Salvadori D.M.F., Rech C.M., Oliveira D.P. and Umbuzeiro G.A. (2007), Mutagenic and carcinogenic potential of a textile azo dye processing plant effluent that impacts a drinking water source, Mutat. Res. Genet. Toxicol. Environ. Mutagen, 626, 53-60.

Demiral H., Demiral I., Karabacakoğlu B. and Tümsek F. (2011), Production of activated carbon from olive bagasse by physical activation, Chemical Engineering Research and Design, 89, 206-213.

Deng H., Lu J., Li G., Zhang G. and Wang X. (2011), Adsorption of methylene blue on adsorbent materials produced from cotton stalk, Chemical Engineering Journal, 172, 326-334.

Djilani C., Zaghdoudi R., Djazi F., Bouchekima B., Lallam A., Modarressi A. and Rogalski M. (2015), Adsorption of dyes on activated carbon prepared from apricot stones and commercial activated carbon, Journal of Taiwan Institute Chemical Engineering ,53,112-121.

Dolas H., Sahin O., Saka C. and Demir H. (2011), A new method on producing high surface area activated carbon: the effect of salt on the surface area and the pore size distribution of activated carbon prepared from pistachio shell, Chemical Engineering Journal, 166 , 191-197.

Dutta S., Bhattacharyya A., Ganguly A., Gupta S. and Basu S. (2011), Application of response surface methodology for preparation of low-cost adsorbent from citrus fruit peel and for removal of methylene blue, Desalination 275, 26-36.

El Nemr A., Abdelwahab O., El-Sikaily A. and Khaled A. (2009), Removal of direct blue-86 from aqueous solution by new activated carbon developed from orange peel, Journal of Hazardous Materials, 161, 102-110.

El-Sayed G.O. (2011), Removal of methylene blue and crystal violet from aqueous solutions by palm kernel fiber, Desalination, 272, 225-232.

Foo K.Y. (2012), Preparation, characterization and evaluation of adsorptive properties of orange peel based activated carbon via microwave induced $\mathrm{K}_{2} \mathrm{CO}_{3}$ activation, Bioresource Technology, 104, 679-686.

Foo K.Y. and Hameed B.H. (2012), Coconut husk derived activated carbon via microwave induced activation: Effects of activation agents, preparation parameters and adsorption performance, Chemical Engineering Journal, 184, 57-65.

Ghaedi M., Pakniat M., Mahmoudi Z., Hajati S., Sahraei R. and Daneshfar A. (2014), Synthesis of nickel sulfide nanoparticles loaded on activated carbon as a novel adsorbent for the competitive removal of Methylene blue and Safranin-O., Spectrochim. Acta A: Mol. Biomol. Spectrosc, 123, 402-409.

Gürses A., Hassani A., Kirans M., Acisli Ö. and Karaca S. (2014), Removal of methylene blue from aqueous solution using by untreated lignite as potential low-cost adsorbent: Kinetic, thermodynamic and equilibrium approach, Journal of Water Process Engineering, 2, 10-21.

Hajati S., Ghaedi M., Karimi F., Barazesh B., Sahraei R. and Daneshfar A. (2014), Competitive adsorption of direct yellow 12 and reactive 012 on ZnS:Mn nanoparticles loaded on activated carbon as novel adsorbent, Journal of Industrial Engineering Chemistry, 20, 564-571.

Hameed B.H. and El-Khaiary M.I. (2008), Removal of basic dye from aqueous medium using a novel agricultural waste material: pumpkin seed hull, Journal of Hazardous Material, 155, 601-609. 
Hameed B.H., Ahmad A.L. and Latiff K.N.A. (2007), Adsorption of basic dye (methylene blue) onto activated carbon prepared from rattan sawdust, Dyes and Pigments, 75, 143-149.

Hameed B.H., Din A.T.M. and Ahmad A.L. (2007), Adsorption of methylene blue onto bamboo-based activated carbon: kinetics and equilibrium studies, Journal of Hazardous Material, 141, 819-825.

Hazzaa R. and Hussein M. (2015), Adsorption of cationic dye from aqueous solution onto activated carbon prepared from olive stones. Environmental Technology and Innovation, 4, 36-51.

Kavitha D. and Namasivayam C. (2007), Experimental and kinetic studies on methylene blue adsorption by coir pith carbon, Journal Bioresource Technology 98, 14-21.

Li Y., Du Q., Liu T., Peng X., Wang J., Sun J., Wang Y., Wu S., Wang Z., Xia Y. and Xia L. (2013), Comparative study of methylene blue dye adsorption onto activated carbon, graphene oxide, and carbon nanotubes, Chemical Engineering Research and Design, 91, 361-368.

McKay G. and Ho Y.S. (1999), Pseudo-second-order model for sorption processes, Process Biochem, 34, 451-465.

Mi-Hwa B., ljagbemi B.C.O., Se Jin O. and Kim D.S. (2010), Removal of malachite green from aqueous solution using degreased coffee bean, Journal of Hazardous Material, 176, 820-828.

Rafatullaha M., Sulaiman O., Hashima R. and Ahmad A. (2010), Adsorption of methylene blue on low-cost adsorbents: A review, Journal of Hazardous Material, 177, 70-80.

Reddy P.M.K, Krushnamurty K., Mahammadunnisa S.K., Dayamani A., Subrahmanyam C. (2015), Preparation of activated carbons from bio-waste: effect of surface functional groups on methylene blue adsorption, International Journal of Environmental Science and Technology, 12, 1363-1372.

Salleh M.A.M., Mahmoud D.K., Karim W.A. and Idris A. (2011), Cationic anionic dye adsorption by agricultural solid waste: a comprehensive review, Desalination, 280, 1-13.

Spahisa N., Addounb A., Mahmoudia H. and Ghaffourc N. (2008), Purification of water by activated carbon prepared from olive stones, Desalination, 222 ,519-527.

Tan I.A.W., Ahmad A.L. and Hameed B.H. (2008), Adsorption of basic dye on high-surface area activated carbon prepared from coconut husk: equilibrium, kinetic and thermodynamic studies, Journal of Hazardous Material, 154, 337-346.

Tan I.A.W., Hameed B.H. and Ahmad A.L. (2007), Equilibrium and kinetic studies on basic dye adsorption by oil palm fibre activated carbon, Chemical Engineering Journal, 127, 111-119.

Vučurović V.M., Razmovski R.N., DMiljić U. and Puškaš V.S.(2014), Removal of cationic and anionic azodyes from aqueous solutions by adsorption on maize stem tissue, Journal of Taiwan Institute Chemical Engineering, 45, 1700-1708.

Wang S. and Zhu Z.H. (2007), Effects of acidic treatment of activated carbons on dye adsorption, Dyes and Pigments, 75, 306-314.

Yang J. and Qiu K. (2010), Preparation of activated carbons from walnut shells via vacuum chemical activation and their application for methylene blue removal, Chemical Engineering Journal, 165, 209-217.

Yener J., Kopac T., Dogu G. and Dogu T. (2008), Dynamic analysis of sorption of Methylene Blue dye on granular and powdered activated carbon, Chemical Engineering Journal, 144, 400-406.

Yu L. and Luo Y.(2014), The adsorption mechanism of anionic and cationic dyes by Jerusalem artichoke stalk-based mesoporous activated carbon, Journal of Environmental and Chemical Engineering, 2, 220-229. 